\title{
Representações e discursividades da educação na comunicação
}

Fernanda Elouise Budag

Docente da Faculdade Paulus de Tecnologia e Comunicação (FAPCOM) e da Universidade São Judas Tadeu (USJT). Coordenadora dos cursos de Pós-graduação Lato Sensu da FAPCOM e do grupo de estudos Narrativas, consumo e marcas: aproximações na contemporaneidade (FAPCOM).

E-mail: fernanda.budag@gmail.com

Resumo: A partir da ótica das teorias sobre narrativa audiovisual e dos estudos em comunicação e educação, lançamos nosso olhar sobre uma série ficcional contemporânea, Merlí, produzida na Espanha, veiculada no Brasil via plataforma de streaming, e cuja temática gira em torno do ambiente e das questões educacionais. Nosso interesse é captar os discursos e representações que ganham, nesse produto midiático recente, a figura do professor e a imagem da educação; particularmente, do docente e do ensino de Filosofia. Empreendendo uma reflexão eminentemente teórica a partir do objeto empírico situado, questionamos se há a reprodução de estereótipos da docência, ou a sua quebra; e quais são os enunciados hoje construídos em torno da educação.

Palavras-chave: comunicação; série ficcional; narrativa audiovisual; educação; comunicação e educação.
Abstract: From the perspective of theories on audiovisual narrative and studies on communication and education, we analyze a contemporary fictional TV show, Merlí, produced in Spain, aired in Brazil via a streaming platform, and whose theme approaches the educational environment and its issues. Our interest is to capture the speeches and representations that gain, in this recent media product, the figure of the teacher and the image of education; particularly the teacher and the teaching of Philosophy. Undertaking a theoretical reflection of the situated empirical object, we question if there is either a reproduction of teaching stereotypes, or their breaking; and what are the statements currently built on education.

Keywords: communication; fictional series; audiovisual narrative; education; communication and education. 


\section{INTRODUÇÃO}

Norteamos nossas reflexões a partir da concepção de Morin $^{1}$ de que a "educação deve contribuir para a autoformação da pessoa (ensinar a assumir a condição humana, ensinar a viver) e ensinar como se tornar cidadão". Nisso, entendemos que o educador é encarado no espaço da sala de aula como um interlocutor mais qualificado para dialogar com seus estudantes e ajudá-los em sua formação. Mais, particularmente, sobre a Filosofia, enquanto "[...] o estudo e o conhecimento das coisas e de suas causas" ${ }^{2}$, compreendemos que seu ensino se prestaria, portanto, a fazer o estudante questionar a realidade.

É nesse contexto da educação em Filosofia que se desenrola a série Merlí, nosso objeto empírico de estudo. Atendendo à especificidade do objeto da comunicação, que ao mesmo tempo permite estudar o produto comunicacional em si (a série) como também o tema que o produto aborda (a educação e o ensino de Filosofia neste caso), concebemos como nosso objeto de estudo os discursos e as representações que ganham, nesse produto midiático, a figura do professor e a imagem da educação; particularmente, do docente e do ensino de Filosofia.

Nesse sentido, nosso texto se desenrola da seguinte maneira: primeiro introduzimos a série, seu enredo, personagens e sua estrutura narrativa para, na sequência, traçarmos nossas considerações sobre as representações e os discursos sobre a educação, o professor e o ensino de Filosofia ali presentes.

1. MORIN, Edgar. A cabeça bem-feita: repensar a reforma, reformar o pensamento. 20. ed. Rio de Janeiro: Bertrand Brasil, 2012, p. 65.

2. WILLIAMS, Raymond. Palavras-chave: um vocabulário de cultura e sociedade. São Paulo: Boitempo, 2007, p. 183.

3. MERLÍ. In: WIKIPEDIA. Disponível em: https://pt. wikipedia.org/wiki/Merl\%C3\%AD_(série). Acesso em: 12 jan. 2020.

4. IMDB. Merlí. Disponível em: http://www.imdb.com/ title/tt4580372/. Acesso em: 11 jan. 2020.

\section{CONTEXTUALIZANDO A SÉRIE MERLÍ́ E SUA NARRATIVA}

Consoante ao já situado tema, assumimos como objeto empírico de observação e análise a série de ficção Merlí e, neste momento, abrimos espaço para contextualizar suas condições de produção, enredo, estrutura narrativa e protagonista. Merli consiste em uma produção espanhola, da Catalunha, criada e escrita por Héctor Lozano e dirigida por Eduard Cortés. Estreou no local de origem em setembro de 2015, pelo canal TV3, e teve os seus direitos de exibição para América Latina e Estados Unidos comprados pela Netflix, sendo exibida no Brasil pela plataforma de streaming desde dezembro de 2016.

A série, que conta com três temporadas (primeira e segunda com 13 episódios cada e terceira com 14), totalizando 40 episódios até a conclusão de sua trama, conquistou bons índices de audiência na televisão catalã. Registrou uma média de 18,3\% de share, com 561 mil espectadores, durante a primeira temporada, exibida de setembro a dezembro de 2015; e alcançou uma média de 19,5\% de share, com 513 mil espectadores, durante a segunda temporada, veiculada entre setembro e dezembro de $2016^{3}$. A produção também é reconhecida por ter recebido um prêmio e indicações a prêmios. Foi nomeada ao Feroz Awards (Espanha), em 2017, na categoria melhor série dramática; ao Zapping Awards, também em 2017, na categoria de melhor ator; e foi vencedora do prêmio de Best TV show na edição de 2017 do Turia Awards ${ }^{4}$. 
Classificada no gênero drama, o nome que batiza a série, Merlí, corresponde ao primeiro nome do professor de Filosofia que a protagoniza, Merlí Bergeron, o qual se caracteriza como um docente que usa recursos didáticos menos convencionais e incentiva a autonomia de pensamento dos alunos. Sendo esse o argumento central da trama, ela é ambientada em uma escola de Barcelona (Espanha), o Instituto Àngel Guimerà.

Em essência, enquanto o professor busca ajudar seus alunos a enfrentarem seus dilemas através da Filosofia, a série procura aproximar a Filosofia do público em geral. Cada episódio, ao longo de todas as temporadas, é fundamentado nas ideias de algum pensador ou alguma escola filosófica em particular, que funcionam como fios condutores para os eventos na série. Por exemplo, já no primeiro episódio da primeira temporada, no segundo dia de aula, professor Merlí conduz seus alunos para fora da sala de aula formal e vai caminhando por outros espaços da escola, momento em que fala sobre os Peripatéticos, como eram chamados os discípulos de Aristóteles que, por sua vez, justamente os ensinava ao ar livre, lendo e falando enquanto caminhava; prática, portanto, que Merlí estava representando na aula em questão.

No primeiro episódio, a série dá a conhecer Merlí como um homem divorciado, desempregado, recém-despejado de seu apartamento alugado e forçado a ir morar com sua mãe. Ou seja, é retratado num momento ápice de fracasso em sua vida. Ainda no primeiro episódio, contudo, já começa uma virada ao menos em um aspecto nessa sua jornada, até então, de insucesso, quando é chamado para a vaga de professor substituto de Filosofia na escola em que estuda seu filho Bruno.

Como forma de continuarmos introduzindo melhor a série, para no próximo tópico enfrentarmos efetivamente a abordagem do discurso e das representações da educação ali presentes - que é o que de fato nos interessa -, continuamos nossa jornada sobre a série da perspectiva da narrativa. Isso porque entendemos que a estruturação da narrativa e a combinação de seus elementos são a grande sustentação dos discursos que nos importam analisar. Em outros termos, começamos com um olhar sobre os elementos fundamentais de uma narrativa, optando por nos focar o entendimento da construção narrativa dos episódios da série (suas partes) e a compreensão de um desses elementos fundamentais, que é o protagonista, Merlí. Este, inclusive, por dar nome à série, de antemão evidencia sua relevância na trama e justifica nossa escolha. Mais ainda: concentramos nossa atenção nesses aspectos por entendermos que, contextualizando-os, antecipamos e revelamos indiretamente também sobre os discursos e representações da educação, nos quais nos aprofundamos na sequência, por ser Merlí o porta-voz dessas várias vozes e porque, como apresentamos a seguir, defendemos que constitui efetivamente a dimensão dessa ficção.

Ainda que Syd Field ${ }^{5}$ escreva da perspectiva do roteiro para o cinema, acreditamos que seu conceito de linha narrativa presta-se para a análise de roteiro de uma série televisiva. $\mathrm{O}$ autor entende linha narrativa como a combinação das várias cenas e pontos previstos que dão forma e lógica ao todo das sequências de eventos que é o roteiro ${ }^{6}$. Nesse sentido, aqui interessa-nos menos o entendimento da linha narrativa da série como um todo e mais a linha narrativa de cada episódio de Merlí.

5. FIELD, Syd. Roteiro: os fundamentos do roteirismo. Curitiba: Arte \& Letra, 2009. 
Em termos de como se dá a construção de sua linha narrativa, sublinhamos novamente que cada episódio dessa ficção é fundamentado nas ideias de algum pensador ou alguma escola filosófica em particular, que funcionam como fios condutores para os eventos na trama. Havendo exceções, mas tendo esse norte, enxergamos, na grande maioria dos episódios (que possuem aproximadamente entre 43 e 50 minutos), um padrão estrutural, que se dá a partir da distribuição da história em três espécies de blocos.

No primeiro bloco, os minutos iniciais costumam ser usados para a exposição teórica de Merlí em sala de aula sobre o tema do dia: as ideias de algum autor ou de um paradigma filosófico. Às vezes a exposição do tema em pauta não se inicia especificamente na sala de aula, mas de todo modo ele é apresentado nesse tempo inicial. Já no que estamos chamando de segundo bloco, o mais extenso, há o desenrolar da história, com a continuação de dramas vividos pelos personagens em episódios anteriores ou a introdução de novos. Enfim, acontecem ações que fazem parte do arco narrativo mais amplo da série, mas que, neste bloco, sempre se dão articuladas ao tema do episódio em questão, introduzido no primeiro bloco. Por fim, no terceiro bloco, ocorre o fechamento da temática, amarrando a teoria inicial à prática da história de vida dos personagens vista anteriormente. Geralmente, há nesse terceiro momento uma nova cena em sala de aula com a continuação da explanação do professor sobre o conteúdo teórico que move o episódio, e finaliza com a resolução dramática das ações que estavam em aberto.

Por exemplo, no episódio sobre Maquiavel (terceiro episódio da primeira temporada), Merlí inicia sua explanação em sala de aula questionando: "Como os ricos e poderosos chegam onde estão? São mais espertos? Mais bonitos?” e complementa defendendo "Não. Nada disso. Maquiavel diria, simplesmente, que são mais diabólicos. Se quiser ter sucesso na vida, pise nos outros. Você terá êxito de uma forma pouco honrosa, mas isso não é problema, desde que chegue aonde quer”. Após essa exposição do professor sobre o filósofo, presenciamos na prática as personagens e ações que poderíamos chamar de cunho maquiavélico sendo planejadas e operadas: enquanto a mãe de Merlí, Carmina Calduch, dá a ideia de provocar um acidente com o professor Eugeni para que Bruno seja aprovado na disciplina, o aluno Gerard Piguillem faz intencionalmente uma pergunta inteligente em classe para chamar a atenção da colega Mònica, menina em que ele estava interessado. Essas ações se desenrolam e, ao final, Merlí entra novamente em classe, fecha o conteúdo, e concluem-se as tramas em aberto.

Nesse sentido, o ponto central da narrativa é que, em sua diegese, ao mesmo tempo em que Merlí ensina sobre o conteúdo previsto no plano de ensino da disciplina (ainda que não o siga da maneira tradicional), ensina também sobre/ para a vida, levando os alunos-personagens a refletirem sobre seus pensamentos e atitudes individuais e em sociedade; para além da diegese, parece esperado que esses ensinamentos reflitam extra-diegese, entre os espectadores, alargando o alcance da Filosofia, usualmente fechada entre os muros acadêmicos. No sétimo episódio da segunda temporada, que trata sobre Judith Butler, uma das maiores teóricas feministas e uma das precursoras na defesa do argumento de gênero 
(homem e mulher) enquanto construção social, os alunos Oliver e Bruno, além de serem interpelados pelos temas de identidade de gênero, orientação sexual e papéis sociais em sala de aula, discutem o assunto entre si, extraclasse. Enquanto isso, a audiência é convidada a pensar a respeito desse assunto que está em diálogo com o espírito do tempo contemporâneo, que a série coloca em pauta.

Ainda em relação à diegese narrativa da série, destacamos a construção do protagonista da trama. Enxergamos, obviamente, que Merlí tem uma grande função na narrativa, sempre animando a ação. Desse modo, vemos Merlí como um herói com imperfeições, numa espécie de combinação entre Herói e Anti-herói. Isso considerando herói, em uma de suas assunções arquetípicas, como aquele personagem que conserva virtudes admiráveis e que segue decidido com sua missão ${ }^{7}$. Já o anti-herói enquanto aquela figura, segundo $\operatorname{Vogler}^{8}$, que pode ser marginalizada socialmente, mas com a qual o público se solidariza, ainda que seja cínico ou cometa ações condenáveis. Em nossa leitura, Merlí personifica essa combinação: por um lado, é admirado pelos alunos e firme em seu propósito, que é o ensino da Filosofia de modo que gere encantamento; por outro, é fingido, debochado, desobediente, manipulador e até mesmo, podemos afirmar, imoral, fazendo alusão a episódios em que se relaciona com uma mulher casada; ou quando rouba uma prova para favorecer seu filho; ou ainda quando age por baixo dos panos para conquistar o cargo de professor de reforço desempenhado por Eugeni.

Não obstante costuma agir de modo autocentrado (preocupações egocêntricas, ainda que também com propósitos de ensino), Merlí revela-se particularmente preocupado com a coletividade e alteridade; portanto, empático quanto à dor alheia sempre que se depara com manifestações de machismo, homofobia e transfobia, por exemplo. Por isso, defendemos que Merlí é essa mescla de Herói e Anti-herói; e talvez seja essa sua personalidade complexa e não linear, típica da natureza do ser humano, que promova a sustentação apresentada na narrativa.

\section{A EDUCAÇÃO E O PROFESSOR REPRESENTADOS}

Tendo esse escopo da estrutura narrativa de Merli na base de nosso olhar, dedicamos este espaço restante para nossas reflexões em torno de discursos e representações que a série trabalha sobre o professor, a educação e o ensino de Filosofia.

Historicamente, mapeando filmes, séries estrangeiras ou telenovelas nacionais, podemos localizar que em muitas dessas produções o professor (qualquer um, não apenas de Filosofia) aparece, em essência, como um ser humano de índole exemplar, dono dos melhores conselhos e condutas. Isso estaria na base da grande maioria - ou totalidade - das representações que a categoria social do professor ganha, que aí se desdobram em outros desenhos: professora humilde, professor engraçado, professor "carrasco" etc. Enfim, independente da carcaça que embala o personagem, estaria por trás dela essa figura humana virtuosa, correta. Como já deixamos a entender, esse não seria o caso de Merlí, que não faz questão de ser

7. VOGLER, Christopher A jornada do escritor: estruturas míticas para escritores. 2. ed. Rio de Janeiro: Nova Fronteira, 2009, p. 83. 8. Ibidem. 
uma referência de práticas éticas e socialmente aceitáveis. Podemos ilustrar esses seus comportamentos com os momentos em que trai sua namorada, por exemplo, ou quando manipula pessoas e situações para atender a interesses próprios. Merlí tem uma maneira própria de lidar com as situações da vida, dando seu "jeitinho" e eventualmente criando algum tipo de confusão. Seu filho, inclusive, cria o termo "merlinadas" para se referir a atitudes típicas de Merlí. Nesses termos, o personagem enriquece ao ganhar traços mais complexos da natureza humana.

Podemos dizer que a série inova consideravelmente em relação a outras narrativas seriadas ficcionais precedentes que retratam o ambiente escolar, porque não se limita a representar os dramas e conflitos dos jovens, a série também lança luz às inquietudes e desafios dos personagens adultos, sobretudo dos professores.

À frente de toda a sua conduta extraclasse, em sala de aula entendemos que Merlí ganha de fato a representação de professor provocador e instigador dos alunos, para que sejam críticos e saiam de sua zona de conforto, a exemplo de professores retratados em Sociedade dos poetas mortos (1989); Mentes perigosas (1995); O sorriso de Monalisa (2003) e A onda (2008), para citar algumas audiovisualidades consagradas.

Aliás, percebemos referência e/ou homenagem mais direta ao professor John Keating, de Sociedade dos poetas mortos, no sexto episódio da segunda temporada de Merlí. No filme de 1989, que se passa nos anos 1950, Keating, após pedir para que um aluno leia um trecho de uma página do livro da matéria, declara sua discordância em relação ao conteúdo e solicita para que os alunos arranquem a página e todo o capítulo em questão. Em alusão a essa cena clássica, Merlí trabalha com um método semelhante no episódio sobre Judith Butler. O professor está explicando que "de acordo com a teoria dela, o nosso gênero sexual não é nada além de uma construção social”. Feita essa explicação, Merlí, como forma de enfatizar aos alunos a mensagem de que devem ir contra o estabelecido, provoca-os: "rasguem o que acabaram de copiar. Rasguem a norma". E continua:

Merlí: Tudo fora da norma é desconcertante para a sociedade. Eu os fiz rasgar os papéis não porque ela não exista, mas porque não temos que acreditar que esse modelo é o único. Há mulheres masculinas e homossexuais, ou um homem pode se sentir feminino e homossexual ou bissexual etc. Já chega. Temos que deixar para trás esses modelos retrógrados.

Esse discurso sobre o questionamento ao status quo é bastante representativo da identidade de Merlí e bastante recorrente na série. Aparece na aula/episódio sobre Sócrates (episódio 5 da primeira temporada) também:

Merlí: Sócrates foi condenado à morte, acusado de corromper os jovens e de pôr em dúvida a existência dos deuses. Quando a única coisa que ele fazia era questionar as ideias que lhe queriam impor. Faz mais de dois mil anos que o poder nos diz o que fazer e pensar. Querem que sejam submissos e calados.

Por sua constante reincidência, defendemos o quanto este é um discurso que representa o que os produtores da série aspiram passar sobre o professor e a educação. Depreendemos dos implícitos ${ }^{9}$ desse discurso, portanto, que a imagem de professor que a série deseja sustentar é a de um professor inspirador e mobilizador dos estudantes, 
assim como a imagem propagada de educação enquanto prática revolucionária. Com a licença de deslocar o discurso de bell hooks ${ }^{10}$, de sua posição de mulher negra falando sobre a educação, seria o educar como "fundamentalmente político". O estudo enquanto "[...] um ato contra-hegemônico, um modo fundamental de resistir a todas as estratégias brancas de colonização racista" ${ }^{11}$. Ou, simplesmente, o estudo é um modo de resistência e ponto. Resistência a todas as formas de opressão, porque, se o estudante tem acesso ao conhecimento, consegue desenvolver uma consciência crítica e uma autonomia de pensamento que o permite reagir frente a dominações de toda ordem. E os enunciados na série sobre o ensino de Filosofia aparecem ainda mais diretamente relacionados a essa formação discursiva ${ }^{12}$, pelo fato de, através dos debates de temas existenciais humanos elementares, como vida, morte e felicidade, fazer aflorar um senso crítico à sociedade atual e seus valores (ou crise de valores).

A fala do professor Eugeni acusando Merlí de estar corrompendo os alunos; os enunciados do pai do aluno Joan, Jaume Capdevila - "Li as anotações de Filosofia de meu filho. Merlí diz aos alunos o que devem pensar" e "Você [Merlí] põe em dúvida os valores que aprendem em casa. E isso é doutrinamento. Deu-lhe [a Joan] ideias que vão contra os planos que temos para ele" -; e ainda as próprias falas de Merlí - "Só quero que os alunos pensem livremente. O que faço é estimulá-los para que façam perguntas, para que pensem por si mesmos. Eu os acompanho, Toni”"13 são indícios dessa representação da educação de Filosofia como transgressão.

Merlí é um defensor da educação representada pelo conhecimento, pelo saber:

Merlí: Eu defendo que tenham interesse pelas coisas, que tenham curiosidade em saber, pelo conhecimento em si. Interesse pelo estudo em si, não porque são obrigados a isso. Aristóteles disse que o maior saber é aquele que não serve para nada. O saber pelo saber, não para ganhar algo em troca ${ }^{14}$.

Atravessando esses discursos e representações da educação e do professor, enxergamos claramente as noções da educação libertadora de Paulo Freire ${ }^{15}$. Ainda que o contexto de Freire seja da alfabetização de grupos de adultos proletários urbanos ou rurais (nos anos 1960), entendemos que suas noções se aplicam à educação no geral, não apenas de adultos ou da fase de alfabetização.

Freire experimentava procedimentos, métodos e técnicas, sempre conservando a certeza "[...] de que só nas bases populares e com elas, poderíamos realizar algo de sério e autêntico para elas"16. Ele, portanto, fazia partir dos próprios grupos de alfabetizandos os temas e problemas de suas realidades para os debates em sala de aula. Nessa mesma direção na série, entrevemos esse traço da educação libertadora quando o professor Merlí traz para a sala de aula também temas do dia a dia dos alunos. Essa prática pode ser ilustrada com a aula ${ }^{17}$ em que Merlí traz à tona uma reflexão sobre a normalidade, porque sabia que os alunos da classe costumavam rotular como estranho o aluno Ivan. Na ocasião, Merlí amarra o cotidiano e a Filosofia. Trabalha a discussão sobre o normal a partir de Foucault, contextualizando que este teórico era homossexual e que, sendo a homossexualidade considerada anormal em sua época, ele depositou sua experiência pessoal de exclusão social no tratamento teórico da confusão entre o que é o normal
9. "Podemos tirar de um enunciado conteúdos que não constituem, em princípio, o objeto verdadeiro da enunciação, mas que aparecem através dos conteúdos explícitos. É o domínio do implícito" (MAINGUENEAU, 1998, p. 81).

10. HOOKS, bell. Ensinando a transgredir: a educação como prática da liberdade. São Paulo: WMF Martins Fontes, 2013.

11. Ibidem, p. 81.

12. MAIGUENEAU, Dominique. Gênese dos discursos. São Paulo: Parábola Editorial, 2008

13. Episódio da primeira temporada.

14. Episódio 11 da primeira temporada.

15. FREIRE, Paulo. Educação como prática da liberdade. Rio de Janeiro: Paz e Terra, 1967.

16. Ibidem, p. 102.

17. Episódio 7 da primeira temporada. 
e o que é o correto. Finalizando com o questionamento: "quem determina os limites da normalidade? Ou seja, entre a normalidade e a anormalidade?”, Merlí provoca os alunos a repensarem seus comportamentos e julgamentos. Trata-se do dado da realidade conduzindo a teoria e levando à compreensão crítica do aluno. É uma educação integrada à realidade do educando: educação "realmente instrumental, porque integrada ao nosso tempo e ao nosso espaço e levando o homem a refletir sobre sua ontológica vocação de ser sujeito"18.

Outro ponto da educação libertadora que permeia a representação da educação em Merlí é a posição do estudante ativo no processo. Merlí procura estimular a participação do aluno, no mínimo, abrindo espaço para diálogo, dando voz para que participe da construção do conhecimento; como podemos vislumbrar em um trecho da aula sobre os céticos:

Merlí: Os céticos baseavam sua filosofia na prática da "epokhé", suspensão do juízo. Estar atento ao que acontece, mas sem dar conta da realidade. Essa era a filosofia dos céticos.

Marc: Mas a filosofia não é o contrário disso? Questionar a realidade? Fazer com que as coisas aconteçam?

Merlí: Sim. Mas esta filosofia é justamente o contrário. Os céticos não desejavam nada além do silêncio para não se separarem da realidade das coisas. Eles se limitam a observá-las. O cético olha com atenção, examina, considera os fatos e se cala. Não julga. Epokhé19.

Como defende Freire $^{20}$, o desejável na educação é o homem não como paciente do processo, e, sim, sujeito criador do seu pensamento.

Pensávamos numa alfabetização que fosse em si um ato de criação, capaz de desencadear outros atos criadores. Numa alfabetização em que o homem, porque não fosse seu paciente, seu objeto, desenvolvesse a impaciência, a vivacidade, característica dos estados de procura, de invenção e reivindicação ${ }^{21}$.

Merlí carrega um pouco sim a figura do professor dono absoluto do saber, mas não se limita a simplesmente repassar esse conteúdo em aulas estritamente expositivas, como na versão convencional de aula que se conhece. Preocupa-se em utilizar "métodos ativos". Nesse ponto, podemos dizer que Merlí mescla o que Freire ${ }^{22}$ já falava em termos de método ativo com o que se fala hoje sobre o blended learning.

O método ativo de Freire está na proposta de Merlí de uma educação problematizadora e de caráter reflexivo, em contraponto à educação bancária, antidialógica e de memorização mecânica de conteúdos. "[...] Método ativo que fosse capaz de criticizar o homem através do debate de situações desafiadoras, postas diante do grupo, estas situações teriam de ser existenciais para os grupos" ${ }^{23}$.

Já o que se chama hoje de blended learning estaria perpassando as práticas de Merlí no sentido de ser uma modalidade de ensino relacionada a uma aprendizagem menos centrada no professor ${ }^{24}$. Vemos isso quando, na aula sobre os cínicos, provocadores, segundo Merlí, o professor leva os alunos ao shopping e os convoca a espalhar adesivos instigantes pelo espaço, levando-os a refletir 
e também agir. Ou, mais ainda, na figura da professora Silvana, percebemos esse ensino não centralizado no professor quando esta faz uso da projeção de uma enquete de perguntas sobre o conteúdo da disciplina e os alunos, divididos em duas equipes, respondem a enquete via tablet. Seria um procedimento que não apenas introduz a tecnologia digital na sala de aula, mas também a usa de modo a colocar o aluno como ator do processo de aprendizagem.

Para além de Merlí, podemos notar na série o trabalho com outras representações de professores também. Silvana segue na linha de representação encabeçada por Merlí, de professora incentivadora, além de jovem e preocupada com metodologias mais ativas. Eugeni cumpre o estereótipo do professor autoritário e limitado a aulas expositivas; Elisenda, professora estressada e desgostosa com a profissão; enquanto Millán personifica o professor por vocação, mas também cansado com o passar dos anos.

Millán: Quando eu comecei eu adorava esse emprego. Mas lecionar é como casamento. Você começa com entusiasmo, mas, depois, dia a dia, descobre os defeitos e chega o momento em que você já não gosta tanto. E ocorre uma coisa. Você desiste ou se separa. E se desistir da docência, o que farei? ${ }^{25}$

O discurso de Millán, acima, também revela os desafios não apenas da docência, mas da educação pública no país, cujas denúncias permeiam a série esporadicamente. Algumas dessas críticas ao sistema educacional são enunciadas por Merlí; deixando no ar a imagem de formato defasado:

Merlí: O sistema faz todos pensarmos que temos que estudar em Harvard, se não somos fracassados. Você não passa, é doente. É inquieto na sala, é doente. Não podemos pensar que o sistema educacional fracassou? Devemos amarrar as crianças nas cadeiras em uma época com tantas distrações?

Merlí: As salas de aula parecem com as fábricas das quais Adam Smith falava. Hora de entrada, sirene, matérias especializadas e, acima de tudo, o mais importante, a data de fabricação. As crianças entram no sistema por faixa etária. [...] Estamos numa cadeia de produção, com planos de estudos padronizados.

Interpretando o que está colocado nas falas de Merlí, inferimos que ele se mostra bastante consciente das fragilidades do sistema e fala abertamente sobre, seja aos alunos em sala de aula ou a seus colegas na sala dos professores. Ainda que estando dentro do sistema, até mesmo por uma necessidade de trabalho e sobrevivência, Merlí não deixa de colocar luz a essas questões que têm urgência de revisão. A seu modo, procura romper e corrigir essas "falhas" quando segue seu programa não linear para a disciplina, não se atendo estritamente ao plano de ensino engessado pré-estabelecido.

\section{CONSIDERAÇÕES FINAIS}

Como procuramos expor, afirmamos que a principal imagem de docente que a série Merli procura passar, na figura do protagonista-título, é a do professor

24. MATTAR, João. Metodologias ativas: a educação presencial, blended e a distância. São Paulo: Artesanato Educacional, 2017, p. 25.

25. Episódio 11 da primeira temporada. 
inspirador, com uma retórica didática e sedutora, que luta pela educação. Pelas falas na voz do próprio personagem, depreendemos que o grande discurso construído em torno da educação em Filosofia é, sobretudo, o do questionamento, de a Filosofia ser um instrumento para fomentar profundidade e criticidade nas pessoas. Nisso, a educação como um todo é retratada como ferramenta de transformação; que "aumenta nossa capacidade de ser livres", como situa hooks ${ }^{26}$.

No último episódio da série é apresentada uma definição para o "merlinismo". Enquanto uma escola filosófica - tal qual o cinismo, o estoicismo, entre tantas outras -, o merlinismo significaria "aproveitar o tempo sendo feliz; comer e beber para superar a decadência humana”. Essa síntese, em tom de brincadeira, resume a imagem do professor de Filosofia que Merlí representa, um sujeito consciente sobre as questões da existência humana, além de evidenciar um lado eminentemente humano dessa representação, abarcando a boemia e os prazeres do personagem.

Enxergamos que há, sim, certas reproduções de estereótipos da docência tanto do professor oprimido (pelo sistema ou pela passagem do tempo) quanto do professor entusiasta da educação. Por outro lado, vemos que há quebras também da representação estereotipada justamente quando se coloca para circular a imagem de um professor com suas fraquezas típicas humanas. $\mathrm{O}$ herói com imperfeições.

Do ponto de vista do processo de ensino e aprendizagem, entendemos que o ensino de Filosofia de Merlí cumpriu seu papel de fazer seus alunos não se conformarem com o estabelecido e conservarem seu espírito livre, quando vemos, ao final, passados anos, em um reencontro da turma, os alunos, em sua maioria, tendo realizado seus sonhos e sendo cidadãos de suas vidas. Pensamos nesse cumprimento da missão das aulas de Merlí, sobretudo, quando focamos no percurso do aluno Pol, que cursou Filosofia e agora é professor da disciplina. Narrativamente, compreendemos que é um elemento chave para concluir a história e amarrar as pontas da sequência de eventos, produzindo significado. Mas, do ponto de vista do ensino-aprendizagem, é também uma conquista da educação.

Talvez, para o discurso da série ter promovido mais avanços, tenha faltado em Merlía abordagem das questões de maneira mais transdisciplinar, mais complexa ${ }^{27}$. Mas essa "limitação", por seguir a supremacia do conhecimento fragmentado em disciplinas, no caso em questão centrada na disciplina de Filosofia, também está relacionada tanto a uma escolha narrativa de canalizar a história nas aulas de Filosofia, quanto porque reproduz a realidade relativamente universal de um sistema escolar. De todo modo, ainda que de maneira muito branda, assinalamos que vemos em Merli não apenas a educação para a compreensão da Filosofia, mas também a educação "para a compreensão humana" de que fala Morin" ${ }^{28}$, enquanto um saber fundamental para a educação neste século.

Concluímos sublinhando nossa percepção de que a série Merlí está forjada com o olhar voltado aos princípios do campo da comunicação e educação, que, segundo Baccega ${ }^{29}$, deve ser pensado a partir de conceitos "[...] tais como mediações, criticidade, informação e conhecimento, circulação das formas simbólicas, ressignificação da escola e do professor, recepção, entre muitos outros”. Sustentamos essa perspectiva porque a série critica e faz criticar, em variados 
momentos, tanto a mídia quanto a escola e o docente; além de contemplar em sua narrativa as variadas mediações presentes na dinâmica da educação formal.

\section{REFERÊNCIAS BIBLIOGRÁFICAS}

BACCEGA, Maria Aparecida. Da comunicação à comunicação/educação. Comunicação \& Educação, São Paulo, n. 21, p. 7-16, 2001.

FIELD, Syd. Roteiro: os fundamentos do roteirismo. Curitiba: Arte \& Letra, 2009.

FREIRE, Paulo. Educação como prática da liberdade. Rio de Janeiro: Paz e Terra, 1967.

HOOKS, bell. Ensinando a transgredir: a educação como prática da liberdade. São Paulo: WMF Martins Fontes, 2013.

IMDB. Merlí. Disponível em: http://www.imdb.com/title/tt4580372/. Acesso em: 11 jan. 2020.

MAIGUENEAU, Dominique. Gênese dos discursos. São Paulo: Parábola, 2008.

MAINGUENEAU, Dominique. Termos-chave da análise do discurso. Belo Horizonte: Editora UFMG, 1998.

MATTAR, João. Metodologias ativas: a educação presencial, blended e a distância. São Paulo: Artesanato Educacional, 2017.

MERLÍ. In: WIKIPEDIA. Disponível em: https://pt.wikipedia.org/wiki/ Merl\%C3\%AD_(série). Acesso em: 12 jan. 2020.

MORIN, Edgar. Introdução ao pensamento complexo. 3 ed. Porto Alegre: Sulina, 2007.

MORIN, Edgar. Os sete saberes necessários à educação do futuro. São Paulo: Cortez; Brasília, DF: Unesco, 2011.

MORIN, Edgar. A cabeça bem-feita: repensar a reforma, reformar o pensamento. 20. ed. Rio de Janeiro: Bertrand Brasil, 2012.

NETFLIX. Merlí. Disponível em: https://www.netflix.com/title/80134797. Acesso em: 7 jan. 2020.

VOGLER, Christopher. A jornada do escritor: estruturas míticas para escritores. 2. ed. Rio de Janeiro: Nova Fronteira, 2009.

WILLIAMS, Raymond. Palavras-chave: um vocabulário de cultura e sociedade. São Paulo: Boitempo, 2007. 